\title{
Studies on clinical anatomy of the maxillofacial and mandibular regions of the Madras Red sheep (Ovis aries) in India
}

\author{
V. Sundaram ${ }^{1}$, P. Dharani², R. Gnanadevi ${ }^{3}$, R. Kavya ${ }^{3}$ \\ ${ }^{1}$ Department of Basic Veterinary Sciences, School of Veterinary Medicine, Faculty of Medical Sciences, \\ The University of the West Indies, Trinidad and Tobago \\ ${ }^{2}$ College of Veterinary Science, SriVenkateswara Veterinary University, Proddatur, Andra Pradesh, India \\ ${ }^{3}$ Department of Veterinary Anatomy, Madras Veterinary College, Tamilnadu Veterinary and Animal \\ Sciences University, Chennai, India
}

[Received: 28 August 2018; Accepted: 3 October 2018]

Background: The present study aimed to study the clinical anatomy of the maxillofacial and mandibular regions of the Madras Red sheep through the morphometric analysis of some clinically important parameters pertaining to the regional anaesthesia.

Materials and methods: The study was conducted in 20 male and 20 female adult Madras Red sheep around 20-25 kg body weight. Eleven parameters related to the clinical regional anaesthesia of the maxillofacial and the mandibular regions were recorded.

Results: The distance between the facial tuberosity to the infraorbital canal was $2.25 \pm 0.14 \mathrm{~cm}$ in males and $2.14 \pm 0.15 \mathrm{~cm}$ in females. The distance from the infraorbital canal to the root of the alveolar tooth was $1.73 \pm 0.28 \mathrm{~cm}$ in males and $1.73 \pm 0.13 \mathrm{~cm}$ in females. The length and height of the mandibles were $15.37 \pm 0.56 \mathrm{~cm}, 9.00 \pm 0.24 \mathrm{~cm}$ and in males $14.53 \pm 0.24 \mathrm{~cm}, 9.68 \pm 0.16$ $\mathrm{cm}$ in females, respectively. The maximum height of the mandible to the coronoid process, width or height of the mandibular foramen and the distance from the condyloid process to the base of the mandible were recorded as $9.0 \pm 24$, $0.82 \pm 0.05,6.68 \pm 0.19 \mathrm{~cm}$ in males and $9.68 \pm 0.16,0.83 \pm 0.04,6.25 \pm$ $\pm 0.28 \mathrm{~cm}$ in females, respectively.

Conclusions: The present study revealed that most of the parameters showed statistically significant difference between the sexes i.e. the males had higher values. However, from the practical point of view, these differences were meagre. The results were discussed with regard to their clinical applications in various regional anaesthesia performed in maxillofacial and mandibular regions of the Madras Red sheep. (Folia Morphol 2019; 78, 2: 389-393)

Key words: clinical anatomy, Madras Red sheep, maxillofacial region, mandible

Address for correspondence: Dr. V. Sundaram, Department of Basic Veterinary Sciences, School of Veterinary Medicine, Faculty of Medical Sciences, The University of the West Indies, Trinidad and Tobago, tel: 1(868) 645-2640, ext. 4206, fax: 1(868) 662-9341, e-mail: drvenkat1971@gmail.com 


\section{INTRODUCTION}

The regional anatomy is the important branch of anatomy that deals with the form and relationships of various anatomic structures present in that area. It is one of the major foundations of clinical and surgical practice as it enables the clinician/surgeon to visualise the details of the structures relevant to the case at hand [1].

The knowledge of the regional anatomy of the head is crucial due to the presence of the vital organs and structures such as brain, tongue, eye, ears, nose, lips, horn and skull. Due to the presence of these structures, the head function is to coordinate the body, deglutition, olfaction and defence [1]. Numerous investigations were done on the regional anatomy of the head of the domestic animals including ox, horse, sheep, goat and dog $[1,3,4,8,10]$. The morphological variations exhibited between the breeds in the same species and between the sexes within the same breed will always be a hindering factor when the general data of the species is extrapolated to all breeds and sexes of the species. Therefore, the breed- and sex-related studies on the regional anatomy would be more useful for the accurate understanding of the regional anatomy of the head.

The Madras Red sheep is a native breed of Tamil Nadu in India, which contributes tremendously to the rural economy of the state by virtue of their meat and wool production. They are medium-sized, well-built, hair sheep, well known for their known for highquality meat, skin, heat tolerance and adaptability to the local agro-ecological conditions. The standard anatomical details of the sheep are extrapolated to Madras Red sheep since the preliminary anatomical work is very scanty in this breed. The breed and sex related craniometric data of the skulls in this animal would be very useful in clinical practice and regional anaesthesia. Therefore, the present study aimed to study the clinical anatomy of the maxillofacial and mandibular regions of the Madras Red sheep through the morphometric analysis of some clinically important parameters pertaining to the regional anaesthesia.

\section{MATERIALS AND METHODS}

A total number of 40 live apparently healthy adult Madras Red sheep (20 males and 20 females) without any skeletal deformation were first selected during ante-mortem examination at Chennai City Corporation Slaughter House, Perambur, Chennai. The animals were weighed and the age was estimated through

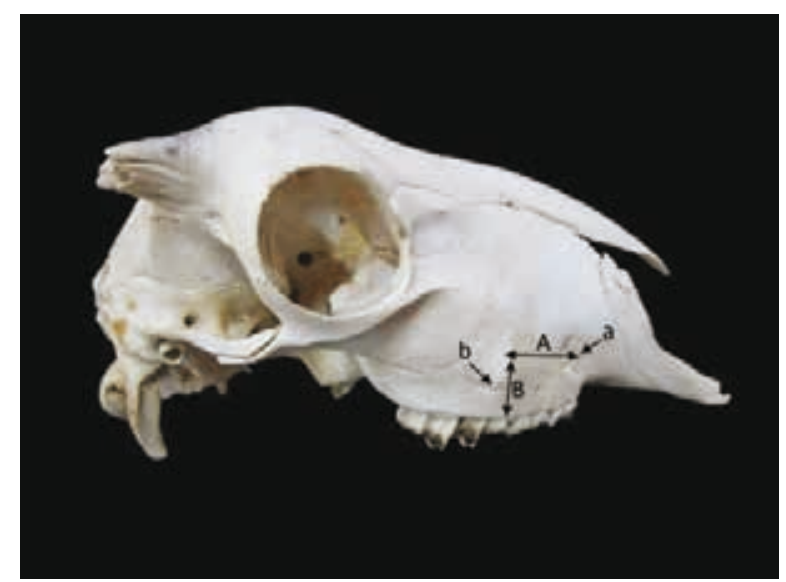

Figure 1. Lateral view of the skull of the Madras Red sheep; A distance between the facial tuberosity to the orbital canal; B distance from the infraorbital canal to the root of the alveolar tooth; $a$ - infraorbital foramen; $b$ - facial tuberosity.

the dentition. All the selected animals were between 18 to 24 months old and their weight ranged from 20 to $25 \mathrm{~kg}$ body weight. The heads of these selected animals were severed at the atlanto-occipital joint after the slaughter and the head was collected and stored in a freezer at $20^{\circ} \mathrm{C}$. Since the animal heads were collected after the slaughter, the ethical approval was not considered as necessary. The frozen heads were processed by hot maceration techniques [13].

Eleven measurements on the maxillofacial and mandibular regions as adapted by Sarma and Devi [12] were measured by using metric ruler and vernier calliper. The landmarks and methodology of each value obtained are described below and shown in Figures $1-3$. The data obtained were analysed by the Student $t$ test through the SPSS (Version 11.0) software and are presented (Table 1).

Measurements of the maxillofacial and mandibular regions:

- A: Distance between the facial tuberosity to the infraorbital canal. It was measured from the level of the most lateral bulging of the facial tuberosity to mid-level of the infraorbital canal;

- B: Distance from the infraorbital canal to the root of alveolar tooth. The measurement was taken mid-level of the infraorbital canal to the root of the alveolar tooth;

- C: Length of the mandible. It was estimated by measuring from the cranial extremity of the alveolar root of the lower incisors to the caudal border of the mandible;

- D: Distance from the lateral alveolar root to the mental foramen. It was estimated as the shortest 


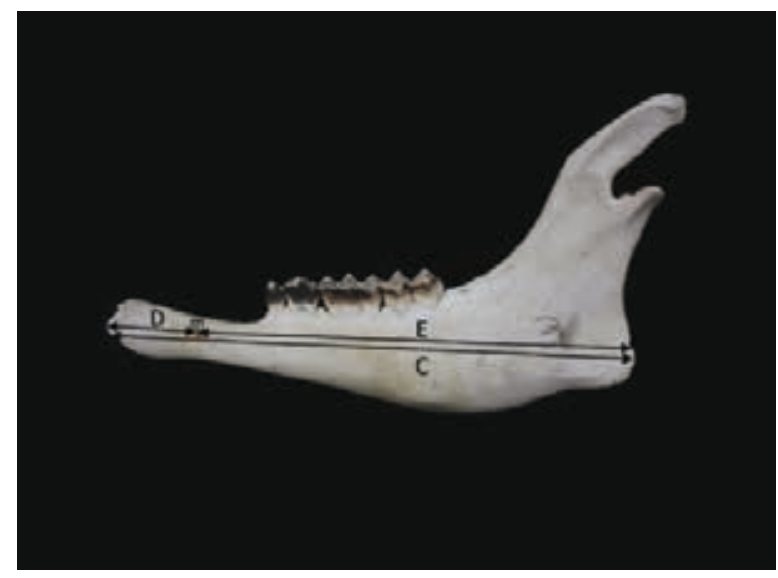

Figure 2. Lateral view of the mandible of the Madras Red sheep; $\mathrm{C}$ - length of the mandible; $\mathrm{D}$ - distance from the lateral root to the mental foramen; $\mathrm{E}$ - distance from the mental foramen to the caudal border of the mandible.

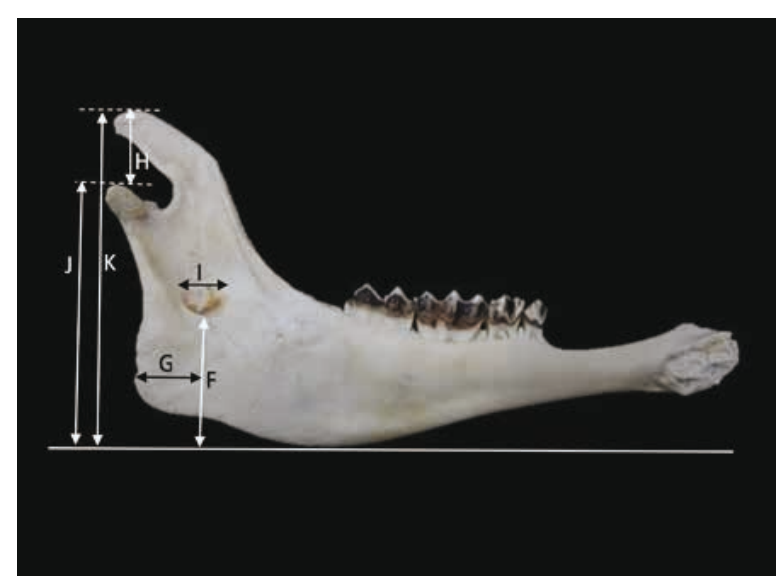

Figure 3. Medial view of the mandible of the Madras Red sheep; F distance of the mandibular foramen to the base of the mandible. The base of the mandible is estimated from a horizontal line drawn from the level of convexity present at the ventral margin of the mandible; $\mathrm{G}$ - distance from the caudal border of the mandible to the middle of the vertical line produced by the $\mathrm{F}$ as described above; $\mathrm{H}$ - height of the mandible to the condyloid process; I — width of the mandibular foramen; $\mathrm{J}$ - distance from the condyloid process to the base of the mandible; $\mathrm{K}$ - maximum height of the mandible.

distance from the mental foramen to the lateral end of the alveolar root of the lower incisor;

- E: Distance from the mental foramen to the caudal border of the mandible. It was taken from the level of the mental foramen to the extreme caudal border of the mandible;

- F: Distance of the mandibular foramen to the base of the mandible. It was estimated as the vertical line from the ventral limit of the mandibular foramen to the base of the mandible. The base of
Table 1. The measurements of the maxilla-facial and the mandibular regions of Madras Red sheep in cm (mean \pm SE)

\begin{tabular}{lcc}
\hline Parameters* $^{*}$ & Male & Female \\
\hline A & $2.25 \pm 0.15^{\mathrm{NS}}$ & $2.14 \pm 0.14^{\mathrm{NS}}$ \\
B & $1.73 \pm 0.28^{\mathrm{NS}}$ & $1.73 \pm 0.13^{\mathrm{NS}}$ \\
C & $15.37 \pm 0.56^{* * *}$ & $14.53 \pm 0.24^{* * *}$ \\
D & $2.20 \pm 0.34^{* *}$ & $1.87 \pm 0.21^{* *}$ \\
E & $12.30 \pm 0.46^{* * *}$ & $11.53 \pm 0.14^{* * *}$ \\
F & $3.63 \pm 0.14^{* * *}$ & $3.48 \pm 0.12^{* * *}$ \\
G & $1.85 \pm 0.16^{* * *}$ & $1.60 \pm 0.10^{* * *}$ \\
H & $2.88 \pm 0.24^{* *}$ & $2.68 \pm 0.11^{* *}$ \\
I & $0.83 \pm 0.05^{\mathrm{NS}}$ & $0.82 \pm 0.04^{\mathrm{NS}}$ \\
$\mathrm{J}$ & $6.68 \pm 0.19^{* * *}$ & $6.25 \pm 0.28^{* * *}$ \\
$\mathrm{~K}$ & $9.00 \pm 0.24^{* * *}$ & $9.68 \pm 0.16^{* * *}$ \\
\hline
\end{tabular}

${ }^{*}$ As described in alphabetical order in materials and methods; NS - not significant $(p \geq 0.05) ; *$ Significant $(p \geq 0.05) ; * * *$ Highly significant $(p \leq 0.01) ; S E$ - standard error

the mandible is estimated from a horizontal line drawn from the level of convexity present at the ventral margin of the mandible;

- G: Distance from the caudal border of the mandible to the middle of the vertical line produced by $\mathrm{F}$ as described above;

- $\mathrm{H}$ : Height of the mandible from the condyloid process to the coronoid process;

— I: Width of the mandibular foramen;

- J: Distance from the condyloid process to the base of the mandible;

- K: Maximum height of the mandible taken from the basal level of the mandible to the highest level of the coronoid process.

\section{RESULTS AND DISCUSSION}

The several parameters showed statistically significant differences between the sexes as shown in the Table 1.

The distance between the most lateral bulging of the facial tuberosity and the infraorbital canal was $2.25 \pm 0.14 \mathrm{~cm}$ in males and $2.14 \pm 0.15 \mathrm{~cm}$ in females. Distance from the infraorbital canal to the root of the alveolar tooth was recorded as $1.73 \pm$ $\pm 0.28 \mathrm{~cm}$ in males and $1.73 \pm 0.13 \mathrm{~cm}$ in females. Both the measurements did not shown any difference statistically between the sexes in the present study. The facial tuberosity of the Madras Red sheep was prominent and placed at the level of $5^{\text {th }}$ cheek tooth as in other sheep breeds [7], whereas it was located at 
the junction of the $4^{\text {th }}$ and $5^{\text {th }}$ cheek teeth in Kagani goats [11] and above the $3^{\text {rd }}$ cheek tooth in ox [2]. The distance from the facial tuberosity to the infraorbital canal and the distance from the infraorbital canal to the root of the alveolar tooth in the present study were $2.25 \pm 0.15 \mathrm{~cm}$ and $2.14 \pm 0.14 \mathrm{~cm}$ and $1.73 \pm$ $\pm 0.28 \mathrm{~cm}$ and $1.73 \pm 0.13 \mathrm{~cm}$, respectively, whereas values reported in Mehraban sheep [4] were $1.87 \pm$ $\pm 0.09 \mathrm{~cm}$ and $1.63 \pm 0.04 \mathrm{~cm}$ and $2.36 \pm 0.03 \mathrm{~cm}$ and $2.06 \pm 0.26 \mathrm{~cm}$ in Bakerwali goats [11]. The above data are of clinical importance because the facial tuberosity is very prominent even in live animals and acts as a guide for tracking the infraorbital nerve, and necessary for the desensitisation which affects the skin of the upper lip, nostril and face on that side of the level of the foramen. The infraorbital nerve is a continuation of the maxillary division of the trigeminal nerve passes through infraorbital canal; it emerges out at the level of the infraorbital foramen, and supplies the sensory innervation to the skin of the upper lip, nostril and face on that side of the level of the infraorbital foramen. The infraorbital canal is measured 5-6 $\mathrm{cm}$ along a line passing forward and downward from the anterior end of the facial crest to the infraorbital foramen in horses [3], whereas the infraorbital foramen is located $3 \mathrm{~cm}$ above the gum line of the first cheek tooth and slightly rostral to it in cattle [6]. The injection of local anaesthetic agents within the canal via the infraorbital foramen will lead to analgesia of the incisor, canine and first two premolars. Moreover, the infra-orbital foramen was located directly dorsal to the second or junction of the first and second upper premolar in Madras Red sheep as in Maradi goats [9]. This information coupled with the observed distance of $1.73 \mathrm{~cm}$ in between the root of the teeth and the foramen in the present study would prove a vital guide to administering the infra-orbital nerve block in the Madras Red sheep.

The distance from the lateral alveolar root to the mental foramen was recorded as $2.20 \pm 0.34 \mathrm{~cm}$ in males and $1.87 \pm 0.21 \mathrm{~cm}$ in females (Fig. 2, Table 1) whereas it was $1.6 \pm 0.22 \mathrm{~cm}$ and $2.0 \pm 0.3 \mathrm{~cm}$ in West African Dwarf goats and Maradi goats of Nigeria, respectively $[8,9]$. It is an important landmark for the locating the mental nerve for mental nerve block in Madras Red sheep. The measurements related to mandible, namely, mandibular length, distance from the lateral alveolar root to the mental foramen and distance from the mental foramen to the caudal border of the mandible recorded in the present study would be useful to the practitioners in confirmation of the mental nerve. All the measurements stated above regarding mandibles showed statistically significant differences between the males and females i.e. the males showed higher values. However, the differences will be meagre when considering the practical point of view. The anaesthetic drugs can be injected in the anterior aspect of the mandibular canal to desensitise mental aspect of the mandibular nerve. This will ensure the loss of sensation of the lower incisors, premolar and lower lip on that side [3].

The mandibular length of $15.37 \pm 0.56 \mathrm{~cm}$ in males and $14.53 \pm 0.24 \mathrm{~cm}$ in females and the maximum mandibular height of $9.0 \pm 0.24 \mathrm{~cm}$, males and $9.68 \pm 0.16 \mathrm{~cm}$ in females were less than the values reported in the Mehraban sheep $15.76 \pm 2.25 \mathrm{~cm}$ and $9.57 \pm 2.71 \mathrm{~cm}$, respectively [5]. However, the values were higher than West African Dwarfs goats of Nigeria, which were $12.00 \pm 1.89 \mathrm{~cm}$ and $6.90 \pm$ $1.09 \mathrm{~cm}$, respectively [8] and the black Bengal goat $14.21 \pm 0.98 \mathrm{~cm}$ and $8.83 \pm 0.57 \mathrm{~cm}$ [14]

The mandibular nerve block is used to examine the mandibular nerve during the clinical examinations and surgical procedures involving the alveoli and teeth of the lower jaw in animals [6]. The width/height ratio of mental foramen in the present study can be used to determine the exact area of the mandibular nerve trunk. The distance from the mandibular foramen to the base of the mandible was measured as $3.63 \pm 0.14 \mathrm{~cm}$ males and $3.48 \pm 0.12 \mathrm{~cm}$ in females. The distance from the caudal border of the mandible to the middle of the vertical line drawn downwards from the middle of the mandibular foramen to the base of the mandible was recorded as $1.85 \pm 0.16$ $\mathrm{cm}$ in males and $1.60 \pm 0.10 \mathrm{~cm}$ in females. The same values were recorded as $1.74 \pm 0.33 \mathrm{~cm}$ in Mehraban sheep [5] and $1.47 \pm 0.25 \mathrm{~cm}$ in black Bengal goats [14]. The same data was recorded in horses as $3.0 \mathrm{~cm}$ [3], in dogs 1.5-2 cm [3] and in goats as $1.44 \mathrm{~cm}$ [12]. The above data provided in this study will be useful for the surgeons to locate the site for infiltration of the anaesthetic drugs for the mandibular nerve block in this particular Madras Red sheep.

\section{CONCLUSIONS}

There is no previous information about these parameters in Madras Red sheep, nor in any other sheep breeds in India, to make comparisons. Therefore, the data presented in this study will form a vital baseline for clinical manoeuvres around the head regional an- 
aesthesia in the Madras Red sheep. Further, it will be very useful in further applied research works towards massive improvement in the livestock sector of the international economy.

\section{REFERENCES}

1. Dyce KM, Sack WO, Wensing CJG. Textbook of Veterinary Anatomy. 2nd edn. Elsevier, Philadelphia 1996.

2. Getty R. The Anatomy of the Domestic Animals. Vol. I. Saunders, Philadelphia 1975.

3. Hall LW, Clarke KW. Trim, CM. Wright's Veterinary Anesthesia. 10th edn. ELBS and Baillierre Tindall, London 2000.

4. Karimi I, Onar V, Pazvant G, et al. The Cranial Morphometric and Morphologic Characteristics of Mehraban Sheep in Western Iran. Global Veterinaria. 2011; 6(2): 111-117.

5. Karimi I, Hadipour M, Nikbakht $P$, et al. The Lower awbone of Mehraban Sheep: A descriptive morphometric approach. World's Vet J. 2012; 2(4): 57-60.

6. Lahunta ADE, Habel RE. Applied Veterinary Anatomy. WB Saunders Company; , Philadelphia 1986.

7. May NDS. Anatomy of the Sheep - A dissection manual 3rd ed. University of Queensland Press, St. Lucia 1970.

8. Olopade J, Onwuka S. Some aspects of the clinical anatomy of the mandibular and maxillofacial regions of the west african dwarf goat in nigeria. Int J Morphol. 2005; 23(1), doi: 10.4067/s0717-95022005000100006.

9. Olopade O, Onwuka SK. Osteometric studies of the red sokoto (Maradi) goats (Capra hircus): implication for regional anesthesia of the head. Int J Morphol. 2007; 25(2): 407-410, doi: 10.4067/S0717-95022007000200027.

10. Onar V, Ozcan S, Pazvant G. Skull typology of adult male Kangal dogs. Anat Histol Embryol. 2001; 30(1): 41-48, doi: 10.1046/j.1439-0264.2001. 00292.x, indexed in Pubmed: 11284162.

11. Sarma K. Morphological and craniometrical studies on the skull of kagani goat (Capra hircus) of jammu region. Int J Morphol. 2006; 24(3), doi: 10.4067/s071795022006000400025.

12. Sarma K, Devi J. Studies on clinical anatomy of the mandibular and maxillofacial regions of the bakerwali goat (Capra hircus). Folia Vet. 2012; 56(2): 8-11.

13. Sundaram V, Leon K, Rao S, et al. Hind limb skeleton of the orange rumped agouti (dasyprocta leporina linnaeus, 1758): structural and functional perspective. Ann. Res. Rev. Biol. 2017; 12(2): 1-12, doi: 10.9734/arrb/2017/30949.

14. Uddin M, Ahmed S, Islam K, et al. Clinical Anatomy of the Head Region of the Black Bengal Goat in Bangladesh. Int J Morphol. 2009; 27(4): 1269-1273, doi: 10.4067/s071795022009000400048 . 